\title{
Social Harmony or a Happy Society
}

\author{
W. Julian Korab-Karpowicz \\ Institute of Political Science, University of Opole, Opole, Poland
}

\section{Email address:}

wjkk@uni.opole.edu

\section{To cite this article:}

W. Julian Korab-Karpowicz. Social Harmony or a Happy Society. International Journal of Philosophy. Special Issue: Evolutionity. Vol. 9, No. 3, 2021, pp. 169-177. doi: 10.11648/j.ijp.20210903.18

Received: July 24, 2021; Accepted: August 27, 2021; Published: September 11, 2021

\begin{abstract}
In this paper, I set out to prove that once we correctly identify human nature and organize our world according to the principle of cooperation, we can arrive at a world of social harmony. We can then engage in conscious human evolution, aiming at moral and intellectual perfection. Hence, we can arrive at evolutionity, a new evolutionary epoch which would replace the current conflicting and disharmonious times of postmodernity. The current world disharmony, which can be observed especially in the field of politics and economics, is largely related to the erroneous modern Western philosophical assertions identifying the human being with an individual moved by desires and the will to power, and the phenomenon of life in an endless conflict. An additional influence is provided by the flawed postmodernist conceptions of culture and family. These errors have enormous implications with regard to how we picture the world in which we live. They hinder our evolutionary capacities. I want to show that cooperation is an integral part of human nature, and that the society organized according to the requirements of nature is a truly happy society. I support my argument by statements from Tractatus PoliticoPhilosophicus.
\end{abstract}

Keywords: Moral Perfection, Social Harmony, Social Diversity, Cooperation, Human Nature, Human Evolution, Evolutionity, Happiness, Civilization

\section{Introduction}

"Perfection is expressed in harmony-in the beauty that can be found in nature, art, and human conduct. Today's world is a domain of turbulence and dissonance. There is still much to do on the road toward the moral perfection of humanity.

Given today's technological advancement and the mutual interdependence among states consequent to globalization, the current disharmony in the world is a serious threat to the continued existence of all humankind."

From Tractatus Politico-Philosophius [1].

A perfect world would be a world of harmony. Social harmony is related to an agreement between things that are not necessary the same or similar. It is vital to a good life. It is neither an artificial unity provided by a world sovereign nor the dull equality of a classless society. It is not uniformity or sameness. Social harmony is rather social richness - the special composition of diversity and difference, in which we find mutual complementarity and moral virtue.

Just as in music harmony brings different tones together, social harmony brings members of society together and produces order and peace [2]. Its effect is the development of fine things and fine manners. Our human environment, both natural and cultural, then becomes perfected, and thus beautiful. To live in social harmony means to live in beauty, and the latter can be expressed in the three main aspects of culture: material, social and spiritual. The beauty of the material culture is articulated, among others, in fine-looking design of utensils and other everyday items; the health and good look of our bodies; our cleanliness and tidiness; the way we dress-our fashion; cultivated landscape and splendid architecture; and our scientific and technological achievements; the beauty of social culture, in fine conduct and refined customs; joyful songs and dances; beautiful poetry, literature, music and fine arts; and our excellent social and political organization; and then, the beauty of spiritual culture, in high philosophical and religious ideas; and in our self-knowledge and moral perfection, whose highest expressions are inner purity and other elevated virtues [3].

At the level of human conduct, we find then beauty in politeness, benevolence and love, and these are conductive to happiness. Ultimately, the perfect world, the world of 
harmony, is the world of beauty and joy. This means we live in happy societies.

\section{The Problem of the Current World's Disharmony}

Harmony can be associated with peace, happiness, and physical, social and spiritual beauty. By contrast, disharmony includes something dreadful and ugly, and leads to conflict. It is the domain of dissonance, in which things do not fit together. Usually this is because one wants to forcefully dominate another and the latter opposes the former's domination. Thus, to say this simply, the world of disharmony is the world of struggle, dominance, and power the one which we know so well from everyday news. Can there be another world?

To be sure, in the real world of today, we do not only find the struggle for dominance and power, and moral ugliness related to this, but also a wealth of goodness and beauty in all its cultural aspects, and this can be proven by numerous examples. However, given today's technological advancement, especially in war machinery, as long as this world remains largely the domain of dissonance that is expressed in military build-ups, numerous wars and other conflicts, and the domain of turbulence that is related to frequent changes, revolutions and other unexpected political events, there is indeed a serious threat to the continued existence of all humankind. In the era of globalization and mutual interdependence among states, what happens in one place of the world has an effect on other places, and a local armed conflict can easily turn into a global war. How can we then turn from the current disharmony to the world into a social harmony? How can we come to live in happy societies?

In order to solve a problem, we need always to identify its source. There are some scholars, who often call themselves 'political realists', who say the world disharmony is unsolvable. They claim that social disharmony-particularly disharmony in international relations as the power struggle among states, and domestic disharmony, as the political and economic struggle among individuals and groups-has always existed. They describe all politics as a struggle for power. [4]. For them, wars may be indeed the ugly things, but they occur with inevitable regularity [5]. Their source, they think, is human nature. They believe human beings are egoistic creatures, embodiments of the will to power [6]. Their view, grounded in the political philosophy of modernity, has been very influential until now.

The image of human beings as individuals moved by their desires and the will to power can be found in Hobbes and Nietzsche, but also, in a more disguised form, in Locke and his liberal successors [7]. This image has influenced the development of the social sciences and, in particular, the formation of the discipline of international relations [8]. The question of power, and especially of its distribution and importance in maintaining the status quo, is central to today's postmodern thought.
Social theory is associated with practice. Theories do not only explain; they have also a function of praxis. They are a part of social practice, and thus, they shape our reality. The modern assumptions about human nature have led to the replacement of traditional, classical and Christian, ideals by today's materialistic Western civilization that rapidly develops into a global culture. They have molded human beings into one type and have contributed to the standardization and mechanization of our lives. They replaced by ideologies our capacity of independent reflective thinking. They forced us into a spiritually impoverished existence in a world full of conflicts.

A flawed theory that only partially explains phenomena provides us with conclusions that lead us to a wrong social organization and wrong behaviors. This imposes a moral obligation on every philosopher to correct whatever is wrong and always seek truth.

\section{Human Beings, Culture and Civilization}

The basic characteristic of human beings is that we create culture. Unlike other animals, we do not live in a natural environment, but in the artificial setting of a unique culture culture, which consists of a particular system of education, morality, law, politics, economics, entertainment, philosophy, religion, science, and art. The ability to create culture, or our artificial environment, consisting of material, social and spiritual factors, is a characteristically human trait. Even if we find that some animals are characterized by a high level of organization and develop some customs, they do not, like human beings, continuously and consciously transform their environment, and they do not engage in intellectual and moral reflection upon their lives. Let me now quote two passages from the Tractatus Politico-Philosophicus [1]. Hence forth all references to the Tractatus will contain only its section numbers and will be given in the text.

2.514 "Only human beings are able to seek the truth, to see beauty and harmony in the world, to engage in moral reflection, and to reflect on their own lives."

2.521 "Only in the human world does there exist a difference between good and evil, that is, the sphere of morality. Also, only in reference to the human being can we talk about moral degradation."

Given the above, reducing human beings to one simple characteristic - egoism or a desire or will to power - as many modern philosophers do, does not result in a correct representation of human nature, but merely simplifies it and degrades humans into the level of other animals. In the animal world, desires indeed play a fundamental role, and one can observe there the ruthless struggle for domination and leadership. By contrast, human beings create an artificial, cultural environment that significantly modifies their behavior. They can be very gentle in relation to one another, but they can also behave more violently than savage animals. Individuals or groups can be guided by untrammeled 
selfishness (especially when encouraged to do this by social acceptance) to pursue their desires at the expense of others, and to ruthlessly fight for power and domination, but, thanks to education, they can also improve morally and acquire such traits as honesty, diligence, peacefulness, kindness, and mercy. And in the end they can recognize themselves as spiritual beings.

2.43 "An excellent, fully civilized society is a society of virtue. It consists of ennobled people, cooperating with each other and sharing a sense of community."

Civilization can be defined as culture that reaches a higher level of material, social, and spiritual development [1]. Of the three cultural aspects: material, social and spiritual, the latter is most important. There cannot be a proper perfection of humankind, of which the sign is a fully developed civilization, without peoples' moral perfection as manifested in their virtues and behavior. We can find examples even from recent history of well-organized societies that were equipped with advanced technologies and developed superb arts and sciences, and yet engaged in extreme destruction and genocide, for they fell to a low level of civilization, bordering on barbarism when it came to adherence to ethical principles. For with respect equally to both the individual person and the whole of civilization, we can speak of moral development and of moral degradation. Ultimately it is ethics that is the sign of a civilization. It is the presence of ethics both in the public sphere and in private lives that makes us fully human and civilized beings.

Therefore, when we submit any civilization to an assessment, or when we think about the development of our own country and make plans for its future, we should always consider all three of these cultural aspects (material, social, and spiritual) and not merely the level of economic development or technological advancement. The greatest achievement of humankind is not merely advanced technology or material wealth, but in fact complete civilization-insofar as it includes ethical principles and elevates the whole society up intellectually and morally. It is indeed civilization, particularly in its moral aspect, that provides us with our human dignity and gives us a unique place among all creatures.

\section{On Human Nature}

Our essence is to think-we homo sapiens. Thinking constitutes our true nature. Because of our ability to speak, to discuss issues and to reflect on them, and to include in this reflection thinking about ethical issues, we are not only rational beings, but also moral ones. Moreover, because of our inherent ability to transcend our own desires and biological instincts and to shape our way of life, we are also free beings.

Freedom is not just an absence of restrictions or an ability to do what we like; it is rather the increasing control of human beings over their environmental constraints and over themselves - freedom is self-determination, and also the possibility of self-realization.
Reason, morality, and freedom are our alpha and omega they are the departure point of humanity, but also our great task to be completed: the point of destination. To develop them to a full degree and to recognize our spiritual nature is our human destiny.

11.1 "The purpose of the evolution of life is its fullness and perfection. The evolution of life is a journey to ever greater freedom and moral perfection."

The humanity that reduces its essence to animal desires and the will to power, fabricating hostility and consuming material, social and spiritual resources for military buildup or for excessive consumption, and that is torn by frequent wars and other conflicts, will not fulfill its task any soon. Yet this, which seems to us so difficult and so far away - reaching the point of destination and realizing our destiny - is actually so easy and so close. It is to discover and to properly identify our own human nature, and to implement it in social practice.

We are rational or intelligent beings who can think in a discursive manner, but who are also endowed with intuition that allows us to grasp higher truths; we are moral beings, capable of ethical reflection, of inventing principles governing our behavior, and of morally perfecting ourselves; we are free beings, who can transcend their animal nature, control their desires and shape their lives. And furthermore, we are social beings who can live and develop only in a group, and do this on the basis of a fundamental principle of humanity, which is cooperation.

\section{Cooperation: The First Principle of Humanity}

The philosophy of modernity is established on a myth, which is the social contract said to be made at no specific time or place, among abstract individuals moved by their desires, especially by "a perpetual and restless desire of power after power, that ceases only in death." [9]. As viewed by Hobbes, human beings, subject to blind, mechanistic drives, are moved by desires and ruled by passions. It is by passions such as acquisitiveness, fear, and pride that they are driven to wage war against one another; it is also through passions (especially fear of violent death) and only partly through reason, that they at last want to achieve peace [10]. Their desire for security in the face of growing conflict among them leads them to conclude the social contract and to agree to live in a society under the rule of a sovereign.

However, in contrast to the abstract individuals who enter into the social contract and thus establish a society, the real human being is always a member of a smaller or larger historical community (the most essential component of which is the family). The relationship to a particular community and cooperation within its framework is an inherent, natural context of each individual human life. Without belonging to a community, we could not develop our skills; we would quickly die; and, for that matter, we would not even be born. Hence, we cannot live without being part of a community. At most, we can change the country of our residence and replace 
one community with another.

2.53 "Human beings are by nature social beings. They have a natural disposition to live in a society, cooperate with others, and reap the benefits of social life."

2.531 "The individual as a stand-alone being is a fiction."

We act as a part of a group, but at the same time each of us is an individual being with his own needs and ambitions. In addition to the common group interest, there also exists the self-interest of each of us. These group and individual interests are powerful forces that can stimulate human activities and lead humanity to development. However, on the negative side, they may be related to egoism. Self-interest is a morally neutral notion and has to be distinguished from selfishness or egoism, which is a vice. "Selfishness is not simply love of self but excessive love of self" [11]. Selfishness or egoism means pursuing self-interest regardless of the negative consequences this might have for others, and involves cooperation with others only when it serves our interests.

Let us now assume that people are egoistic individuals and, if we ever act together, it is "not so much for love of our Fellows, as for love of our Selves" [12]. According to this assumption, we interact or cooperate with others only when we perceive in such an action the forwarding of our selfinterest. This self-interest can pertain to achieving a particular goal with others; for example, obtaining food through a common effort, getting rich by banding together to loot someone's property, or defending oneself against an attack in concert with others. If, however, there are no specific self-interests to be achieved, then there will be no need for egoists to cooperate, and each selfish individual, moved by his passions, can live his individual life without having to have any contact with others. It is such a view of human beings and their behavior that emerges from the philosophy of Hobbes and his numerous disciples. But there is probably no view that is further away from the truth.

An egoistic individual can ruthlessly and at the expense of others pursue his own goals and come into unstable relationships with others only if, in his opinion, this will bring him a benefit. Being overwhelmed by the desire of power, he can seek to dominate others and to destroy all competitors who stand in his way. But such an individual will never be more than an ordinary cheater. This is because he hides from others, and also often from himself, the fact that the first principle of humanity is cooperation. Without cooperation no one, whether he is a good person or a bad one, will be able to accomplish anything; he will not even be able to affirm himself in his own humanity.

1.5 "Cooperation (as opposed to conflict or the struggle for power) is the fundamental fact of human existence and the essence of politics."

10.141 "Cooperation is a mutual exchange of services. Within the framework of cooperation, each person and institution in society performs a suitable function."

Let's us look around. This room, where we are now, is the product, and an example, of cooperation. Someone once designed this building, and many others then built and equipped it. We must also look at the clothes we are wearing and consider the upbringing and education we have received, as well as reflect on aspects of the wider world, including our country, our language, and our civilization. All this, to a large extent, we owe to others.

Cooperation is indispensable for human existence and development. In pursuing egoistic goals, we may not want to admit to ourselves a simple truth: namely, that our lives are fundamentally linked to the lives of others and are dependent on them. By our own strength alone and without the efforts of so many, mostly anonymous, other people, we would never been able to transcend our animal state and to develop our culture and civilization.

\section{Diversity and Social Classes}

Society is not merely a collection of individuals. It is a diverse community linked by the bonds of cooperation. It consists of people who differ from each other in their level of affluence, intelligence, and education, as well as their habits and character traits. They all need to work together to achieve individual and common goals. The idea to remove all differences, make all people alike, and arrive at a classless society is neither compatible with human nature nor conductive to social progress. As human beings we all want to be recognized and respected by others. Even if social classes were artificially removed by law, there will always be individuals striving for more wealth, better looks or greater power than others. Therefore, instead of exclusion of a certain class from society, in the form of its abolition, marginalization, or removal from influence in political and economic life, it is better to recognize its real existence and to make it to cooperate for the common benefit of the whole society. Classes are groups of people differing in wealth, education, employment, values and traditions. Distinct social classes are an important element of society's diversity. This is clearly indicated in the Tractatus Politico-Philosophicus:

3.2125 "A classless society can only be an artifice."

3.2126 "A diversity of people, social classes, cultures, religions, and nations, melded together through cooperation, comprises a variety of complementary skills, talents, experiences, and values".

3.214 "The basic values of the three main classes of contemporary society-labor, business, and honor-are freedom, entrepreneurship, and nobility. All these values should be present in a well-organized society and should be represented by certain social groups".

Distinguishing elements related to social classes are their values. These can be summarized as freedom, entrepreneurship, and nobility. Classes are not artificial constructs, but they have roots in human psychology - in the different human values and needs, often related to personal upbringing and family traditions.

Some people value wealth and are ready to devote their life energies to pursue it and take appropriate risks to obtain it. These people can be in general classified as the Business Class. Other people feel that they are well qualified to organize social life and wish to devote their life energies to 
the welfare of society. They are even ready to risk their lives in the defense of their country. Insofar as they want to serve others and not just their own aggrandizement, they are individuals of virtue and honor. They form the Honor Class. Finally, most of us simply want to live a quiet life, devoted to our families and properties. We despise oppression and value our freedom. We just desire to have a stable employment and a decent salary, a recognition in the form of promotion, as well as enjoyable vacations and other small benefits that our employers and the society at large can offer us. These of us who want simply this are presumably the most numerous. They form the Labor Class. There can be one more class, namely of those rather rare individuals, who sincerely want to devote their lives primarily to spiritual pursuits, as thinkers, writers, poets, monks, priests, or other religious or secular spiritual personalities. They form the Spiritual Class. However, as these are individuals of virtue, they can form one class with the Honor Class. They are a part of the society's elite of honor and merit.

6.731 "The elite of honor and merit is the minority group, comprising people who are noble, resourceful, and educated, that in every generation contributes to the maintenance and development of various aspects of culture; and if these people are replaced by others who are less diligent and less talented, culture declines."

In many societies of the past, we would find traditional social classes that could be identified with either Labor, Business, or Honor. These traditional social classes would often develop some form of class egoism and this egoism would in the end often lead to social revolutions and produce their destruction. However, the fact that human beings can develop egoism does not mean that they are bad by nature, nor does the fact that social classes can develop egoism mean that the division of society into social classes should be altogether rejected. There is class egoism, but there is also class benefit.

5.82 'Citizens' nobility comprises the civic virtues: courage, honesty, respect for the law, diligence, and, above all, love of freedom and of one's country."

5.821 "A nation that loses its nobility goes into decline, experiences internal quarrels, becomes divided, and turns into a passive, lifeless collection of people who can be easily manipulated and enslaved."

6.66 "In a society where there is no room for wisdom and nobility, political power is gained by the worst."

Our lives are largely shaped by our cultures. Just as individuals can be educated in virtue and restrain their selfishness, so also can social classes, especially if with time they develop their own distinct moral traditions. As they represent three different but complementary values: Laborfreedom, Business - entrepreneurship, Honor-nobility, they can all contribute to the well-being of society, and this is their benefit. Without their contribution societies decline, materially, socially and spiritually.

If nobility is missing in social and political life, then politics becomes corrupted. It becomes a mere play of different, mainly commercial interests. It is dominated by individuals who lack virtue and often do not have other proper qualifications for leadership [13]. There is also decline of spiritual aspects of life. Social life becomes increasingly pragmatic, professionally oriented, manipulated by media, commercialized and superficial, and there is no place for poetry and for a deeper philosophical or religious reflection. Then, if entrepreneurship is missing and the country's economy is organized by the state administration, we end with inefficiency and eventually with poverty. If there is no freedom, we end with exploitation at the work place or with a political tyranny.

The social classes representing the values of freedom, entrepreneurship, and nobility can be established in a formal way and defined by law, or they can develop in an informal way and be defined by custom and social recognition. In the latter sense they can exist and contribute to the social wellbeing even in a democracy. Their cooperation becomes a unifying factor in the community life of the people. They create a unity out of apparent diversity.

\section{Today's Conflicts and Their Solutions}

People need to cooperate to achieve individual and common goals. The bonds of cooperation break down, however, if there are conflicts among them. People can be divided by different values, especially those related to their distinct civilizations and ideological formations, as well as by their different interests.

1.54 "Cooperation is based on the common good and common values; it is destroyed by quarrels and hatred".

8.7841 "To avoid civilizational conflict, the culture of a society should be based on the dominant native culture, while ensuring tolerance for others."

If incompatible values of different civilizations find themselves in one society, they contribute to that society's divisions and lead to conflicts. Bringing different cultures into close contact and removing from the national one a dominant role, produce the sense that one's own culture is under threat, giving rise to anti-immigrant movements and ethnic clashes, as we have seen in many parts of the world Therefore an appropriate solution to the civilizational conflict is not multiculturalism, which dethrones the dominant national culture, leads to splitting the society into separate cultural groups, each claiming its distinctiveness, and contributes to a potentially unstable and dangerous environment of "culture wars," but nativeculturalism - the principle of domination in society of the native national culture, with tolerance for other cultures. Nativeculturalism is of particular importance for older countries; those that have for centuries developed on the basis of one dominant culture.

There can be conflicts between civilizations and these are called inter-civilizational or between epochs or ideological formations and these are called inter-epochal conflicts. The clash of epochs, in the form of a conflict between epochs: traditional, modern and postmodern, is more fundamental to the understanding of today' world politics than the clash of civilizations [14]. 
Although there were major civilizational differences between the traditional societies of the past, particularly with regard to religion, there were many common values related to all of them. Members of those societies valued family, morality, religiosity and community. These are the main values of a traditional society. In the epochs of modernity and postmodernity, both initiated by the West, these values came under challenge.

7.623 "The greatest moral and cultural loss of modern humanity is the collapse of traditional beliefs that establish moral values in human beings, and their replacement by religious fundamentalism and secular ideologies."

8.7611 "In the name of the truths of reason and empirically verifiable knowledge, modernity refutes truths based on faith and custom. Modern individualism contributes to the destruction of traditional social ties and replaces them with groupings of people with similar interests or an artificially constructed national unity."

8.762 "Postmodernism, in turn, undermines the national unity of the modern state through its notions of diversity and multiculturalism. It weakens the nation-state and deconstructs its sovereignty. By its affirmation of diversity in relation to sexual preferences, it also weakens the traditional family based on heterosexual relationships."

Our time is an era of grave conflicts. Not only there are still traditional, intra-epochal conflicts: political, economic, ethnic, religious, and civilizational, but also there are those that have been introduced by the impact of modernity and postmodernity. The idea that human beings are moved by their desires and motivated solely by interests has weakened human ties and undermined traditional communities. The idea that there is no longer any privileged sexual orientation, but just a diversity of desire, has led to the weakening of traditional family values. Therefore, notwithstanding of their positive impact, both modernity and postmodernity have contributed to social turmoil and to today's world disharmony. Postmodernity, whose practical manifestation today are the processes of globalization, does not bring humanity to a better, more peaceful world.

8.792 "Postmodernity can be regarded as merely a shortlived episode in the history of humankind, but one nonetheless fraught with consequences. Postmodernity, which coincides with globalization and weakens the state, has become an expression of political irrationalism, leading to the disappearance of professional diplomacy and to an era of uncontrolled violence."

8.821 "Our time represents the breakdown of cultural constraints and the triumph of desires. Equipped with the newest technological achievements and the vastest powers, humanity is returning to a state of primitivism."

Solutions to all today's conflicts cannot be discussed here. Let me only address two important issues. First, the solution to today's multisexuality, namely, to the postmodern idea that there is no longer any privileged sexual orientation, just a diversity of desires, is parentsexuality - "the principle of privileging in society the traditional sexual relationship between a man and a woman, who unite to establish a family and to have children" (7.851). It is obvious that without traditional parental sexuality, in the long run any society is doomed to extinction. Should it not die first on its own, it will be dominated or conquered by sexually traditional societies based on large families. Secondly, the solution to today's discord in international relations is political rationalism. It expresses itself in the pragmatism of action, aiming at a good life, and in the knowledge of the highest goals of humanity and of everyday human behavior. Its first principle says that "the main objective of international politics is to build a strong international community based on shared values, respect for international law, and cooperation in advancing the prosperity of all humankind" (9.51). In the world of international harmony, the goal for each state is to work with other states and ensure its own safety and that of its citizens.

The fundamental feature of the traditional (pre-modern) civilization of the West, but also of other ancient civilizations, is the conviction of the unique, rational character of human beings and of human capacity for moral reflection as a consequence of this rational nature. The successful ending of many today's conflicts depends on our capability to return to the classical rationality - to reason, whose activity is not reduced to thinking merely about the optimal use of available resources to achieve the desired goals, but includes a reflection on what is morally right or wrong, and on the meaningful human life. It is through our axiological reflection-rational thinking about values, especially values related to cooperation, freedom, and our destiny - that we can understand what constitutes a good life for us, individual human beings, as well for our communities, and arrive at the idea of a harmonious and happy society.

\section{Happiness and Illusion}

There are some philosophical schools that deny real existence to the observable world and regard it as an illusion. According to their view, the world is unreal and the only reality is the eternal spirit or pure consciousness [15]. It is also present in us as our own self. The illusionary world of sensory experience takes us away from our self and confronts us with everyday life permeated by sorrow. The only way to be liberated from sorrow and to obtain happiness is to turn our mind inwards and regain our self in the process of ascetic practice and meditation. Otherworldliness and the pursuit of individual liberation thus become the main aims for spiritual seekers. Society is seen as a hindrance to the spiritual progress. On the other hand, there are other philosophical schools that reduce reality to the world and the world to the totality of facts [16]. There is no other reality but the observable, material world. Happiness is merely what we can sensually experience as pleasant. It is "a continual satisfaction of desire, from one object to another" [17].

The schools described above both represent a one-sided view of the reality. They define the reality as either facts or the spirit. Let me propose a different view. Reality is a multilevel manifold. The facts that we can observe and the 
spirit that we can experience are two of its dimensions. We need to add one more-values. If our human world is considered, then "the world is the totality of values, rather than the totality of facts" (7.2021).

From the perspective of facts, it makes a real difference whether something is or not, whether an event happens or not, whether we are hungry or not, whether something runs fast or goes slowly. From the perspective of values, it makes a difference whether there is religious tolerance or religious prosecution, whether we have a good or corrupted government, whether something is beautiful or ugly, whether we are at peace or at war. From the perspective of the spirit, it makes difference whether we have developed love or hate, whether we are morally virtuous or fallen, whether we subject our lives to moral and intellectual examination or live without any reflection.

There are three different dimensions of reality-facts, values, spirit (consciousness) - that correspond to the three aspects of culture-material, social, and spiritual. None of them is an illusion. Each in its own way exist and has a vital impact on our lives. They complement each other. For example, if we did not have anything to eat, or if we lived in a society in which there was religious prosecution, then we could not study books of ancient wisdom and pursue freely our spiritual path. The world really exists in all its three dimensions of reality and perhaps in some additional levels that can still be discovered. Each of them is of relative importance. To use the famous example from Vedanta philosophy, if we mistake a rope for a snake at dusk, it does not yet mean that the world is an illusion, for in this case the rope is an observable fact. It truly exists as a material object. So also, if we take a corrupt government for a good one, this is not mean that all politics is an illusion and nothing can be improved. For it makes a real impact on many human lives whether a country is well or badly governed. Consequently, our material and our social world are not illusions. They are vital parts of the overall reality. Reality is the manifold in which facts, values and the spirit are included.

Our world is not an illusion, nor should it be associated with sorrow. For even if there are evens that can make us sad, our world is also the place where we can experience happiness at different levels. Human life is not a continual flow of desires; it is rather a continual flow of experiences. If those are joyful, fulfilling experiences, then our lives are happy. Happiness may be related to both good experiences and our fulfillment or self-realization.

We have come to this world to be happy and, perhaps with the exceptional cases of some incurable illnesses, happiness is obtainable by all. We should work together to provide good experiences to all members of humanity. Each of us deserves a good, fulfilling life. However, we should not expect the same expression of happiness from a child as from a mother, a scientist, or a yogi, for we can experience happiness in different ways and levels. We can indeed be happy in this world as individuals, and as societies. We do not need to liberate ourselves from it. If we strive for perfection, we give priority to the spiritual world. But the quest after the spirit, which is beyond appearances, should not lead us to forsake facts and values, but to build on them. To pursue spiritual fulfillment does not mean that we should neglect other dimensions of reality. They all complement and mutually influence each other.

Happiness is not merely a fleeting moment of pleasure. It does not consist in an identification with mere material objects. But neither can it be reduced to a mystical state that is available only to a few spiritual seekers. Considered as a permanent value, happiness is linked with freedom; that is, with the possibility for individuals and groups to achieve self-realization. Human beings differ in their wealth, level of intelligence and education, age, customs, and character traits. Each community is characterized by an enormous diversity of human talents, skills, and ambitions in life. Some people will find self-realization in a happy family life, some in enlarging their wealth, some in service to humanity, some in pursuing scientific research, some in the religious worship and the quest for God, and finally some in exploring and bringing to fulfillment their inner spiritual nature.

3.411 "A good life is a complete life."

3.4111 "All people have the right to develop their natural talents and utilize their acquired skills, so long as these contribute to their personal development and do not cause harm to others."

Spirituality is a positive transformation of our consciousness and of our attitudes to the external world. Its effect is self-knowledge and moral perfection. To be transformed, human beings need to connect with God or the Eternal reality by prayer and meditation. Without this connection, by our efforts alone, we are usually too weak to overcome our moral weaknesses. Therefore, spirituality is essential to our well-being.

A happy society is a diverse community whose members (individuals and groups) have the opportunity to achieve selfrealization, and thus pursue happiness as they best understand it themselves, and in all of its cultural aspects: materially, socially, and spiritually. A society is happy because of the happiness of its members, and these are happy if they can grow and develop their life possibilities. However, they can never pursue their own happiness at the expense of others, because then we would not have a happy society, but only prosperous individuals or groups within a society. The fundamental moral imperative related to happiness is that our well-being or self-realization can never be associated with a harm done to another human being.

\section{Evolutionary and Evolutionary Consciousness}

To come out of our current critical human condition and to foster human advancement, it is necessary to reveal to humankind its highest goal, which is moral and intellectual perfection. Once we recognize in us inner creative powers, that is, the possibility of our self-creation by the help of practical and speculative reason, we can transit to a new evolutionary 
age - evolutionity. Practical reason gives us an internal directive related to a sense of duty, or more broadly, of righteousness or what is right - the directive, which is independent of any external law and leads us to moral goodness. Speculative reason, in turn, gives an internal cognitive certainty, which is independent of experience and leads us to truth. Through the development of these internal powers, a spiritual transformation and further human evolution are carried out. Reaching evolutionary consciousness, people understand that through their internalization, or internal moral and intellectual development, they are progressively released from their physical and biological conditions, and thus become agents of their own evolution, which is also the next phase of the universe's evolution.

8.79 "Our time is the age of postmodernity and the clash of epochs. But a new age of humanity is rising. It is evolutionity or the evolutionary epoch which replaces modernity and postmodernity."

8.7932 "As we are now entering into the age of evolutionity, we become increasingly aware about our identity and our task, which is to further develop morally and intellectually and to complete human evolution. Through our strive for perfection the world will be transformed."

The further evolution of humanity is connected with the use of science and technology for our bodily-mental development - intelligence, health, longevity, as well as with our cultural development aimed at moral and intellectual perfection. Only such a holistic development-physical, biological, moral and intellectual — can be justified and regarded as fully balanced. High intelligence and bodily fitness are not enough. If intelligent individuals use their minds to serve the material aspects of our existence and at the same time do not adequately develop their morals, they will perform evil acts, and these will be the more harmful to others the more these individuals are equipped with great powers of the latest achievements of science and technology. Therefore, for our further human development, humanity must enter the path of moral goodness. In practice this means everyday kindness, mutual respect, good-heartedness, harmonious cooperation, common friendliness and human brotherhood. Today, just like in the past, it is difficult to fully imagine the future and the great achievements human beings are still capable of. For our further evolution, however, we need not only to understand our great task of moral and intellectual transformation, but also to engage in practical cooperation. The progress of humanity requires both external and internal peace, and appropriate material and social conditions. Their achievement depends on the harmonious working together of individuals, groups, societies and countries at various levels.

It is urgent today that we resolve violent conflicts, put aside the threat of wars, remove media manipulation, improve living conditions, embrace natural and spiritual beauty, and develop further our bodily and mental capabilities. But above all, we must engage consciously in our evolution, in moral and intellectual perfection. It fully depends on ourselves, on the cultural environment that we create and on the quality of our thoughts and ideas, who we will be in the future, and whether we will realize our human destiny.

\section{Conclusion: Happiness and Social Harmony}

Social harmony is social richness-the special composition of diversity and difference, in which we find mutual complementarity and moral virtue. Diversity, difference, complementarity and moral virtue are all prerequisites for cooperation - the first principle of humankind. People can efficiently work together if they are diverse in terms of their skills, if they are different in terms of their social position (some performing leadership roles and others being guided), if by their education and abilities they complement each other, and if their relations are based on justice, mutual respect, friendship, solidarity and other virtues. Social harmony produces order and peace. It helps to achieve common goals. It leads to the development of fine things and fine manners. Its indispensable part is happiness. Social harmony is actualized when all members of society have opportunities for self-realization.

The world can be reduced neither to facts nor to the spirit. It is an integral wholeness, including material, social, and spiritual aspects. As it is our human world, it can be described as the totality of values. The values that we adopt have an impact on personal lives, organize our societies, and shape the course of history. In order to live in a better world - a world that is more prosperous, safer, and happierwe need to reflect on the value of cooperation. Moreover, we need to consider that we are not merely moved by desires as lower animals, but that we can largely control our behavior and are rational, moral, free, and ultimately spiritual beings. Spirituality constitutes the full humanity.

Desires can be increased in human beings by the employment of such cultural means as propaganda and indoctrination. Advertisements can make us desire certain futile things. The fabrication of fear and hate can be used to create enemies and justify military spending. In this world that is far from being perfect, it is essential that we guard our true identity as humans and do not allow ourselves to be transformed into mere consumers or militants. Once we recognize our destiny as humans and realize our evolutionary capacities, we shall transit to evolutionity, a new epoch of social harmony, that shall replace the current conflicting and disharmonious times of postmodernity.

\section{References}

[1] W. Julian Korab-Karpowicz, Tractatus PoliticoPhilosophicus: New Directions for the Future Development of Humankind, New York: Routledge, 2017.

[2] Onkar Prasad, "Sound as Harmony" in ed. S. C. Malik, Dhivani: Nature and Culture of Sound, New Delhi: D. K. Printworld, 1999, pp. 87-90. 
[3] Inner purity, manifested in gentleness, peace, love and joy, can be considered as the highest moral quality. It is the original characteristics of the human soul, as mentioned by Plato in the dialogue Phaedrus. It is what we have lost and to what we can come back. It signifies the inner divinity that according to Vedanta philosophers constitutes our forgotten identity that can be rediscovered by self-reflection and brought again to enfoldment. See Plato, Phaedrus, tr. B. Jowett, Teddington, Middlesex: The Echo Library 2006.

[4] Hans J. Morgenthau, Politics among Nations: The Struggle for Power and Peace, New York: Knopf, 1956, p. 25.

[5] See Christopher Layne, "Kant or Cant: The Myth of Democratic Peace," International Security, 19 (2) 1994.

[6] Neorealists, such as Kenneth Waltz, do not speak directly about human nature, but it is implied in their notion of an egoistic state that is motivated by its security interests, dominance and so on. See Kenneth Waltz, Theory of International Politics, Long Grove: Ill.: Waveland, 2010.

[7] W. Julian Korab-Karpowicz, On the History of Political Philosophy, New York: Routledge 2016, pp. 211-222.

[8] One of the most influential thinkers, whose ideas contributed to the formation of the twentieth century theory of realism in international relations, was Hans Morgenthau, for whom all politics was a struggle for power. Morgenthau, Politics among Nations, p. 25.

[9] Thomas Hobbes, Leviathan [1651] (London: Dent 1973): XI 2 (chapter, paragraph no).

[10] See Korab-Karpowicz, On the History of Political Philosophy, pp. 168-169.

[11] Aristotle, The Politics [c 335 BCE], ed. K. J. Arrow (Harmondsworth: Penguin, 1962), p. 29.

[12] Hobbes, Leviathan, XIII 13.

[13] Someone can argue that we cannot find any social groups that can be regarded as nobility, and that all people pursue always only their egoistic interests. However, cases from history can provide us with evidence to the contrary. We can find many examples of virtuous rulers, upholders of righteousness, who devoted their lives to the service of the well-being of people. See V. R. Mehta, Foundations of Indian Political Thought (From Manu to the Present Day), New Delhi: Manohar 1992.

[14] W. Julian Korab-Karpowicz, "The Clash of Epochs: Traditional, Modern, Postmodern, and Evolutionity," Perspectives on Political Science 48.3 (2019), 170-182.

[15] Swami Sivananda, Jnana Yoga, Shivanandanagar: Divine Life Society, 2007, pp. 45-74.

[16] Ludwing Wittgenstein, Tractatus Logico-Philosophicus [1918], London: Routledge, 1974, passages 1; 2.063.

[17] Hobbes, Leviathan, XI 1.

\section{Biography}

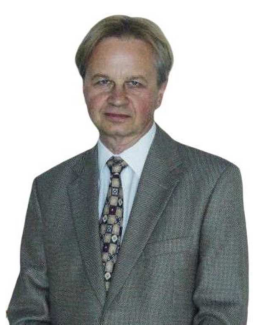

W. Julian Korab-Karpowicz is one of Poland's most renowned philosophers and political thinkers. Brought up in the city of Gdansk, he was a student leader in the Solidarity movement. As a graduate student he was awarded the Scholarship of the Leadership Development Office of the Presbyterian Church (USA). He has received his doctorate in philosophy from the University of Oxford and has taught at many universities, including Anglo-American University of Prague, Texas State University in San Marcos, and Lazarski University in Warsaw. He is the author of several books, including On the History of Political Philosophy (Pearson/Routledge 2012), The Presocratics in the Thought of Martin Heidegger (Peter Lang 2016) and Tractatus Politico-Philosophicus: New Directions for the Future Development of Humankind (Routledge 2017). His books originally written in English and Polish have been translated to Bengali and Arabic. He has received the Personality of the Year Poland 2020 award. 